\title{
F. Brunet, Théophile Gautier, écrivain et voyageur
}

\section{Patrick Berthier}

\section{(Q) OpenEdition}

\section{Journals}

\section{Édition électronique}

URL : http://journals.openedition.org/studifrancesi/10008

DOI : 10.4000/studifrancesi. 10008

ISSN : 2427-5856

\section{Éditeur}

Rosenberg \& Sellier

\section{Édition imprimée}

Date de publication : 1 août 2017

Pagination : 380-381

ISSN : 0039-2944

\section{Référence électronique}

Patrick Berthier, «F. Brunet, Théophile Gautier, écrivain et voyageur », Studi Francesi [En ligne], 182 (LXI I

II) | 2017, mis en ligne le 01 août 2017, consulté le 06 janvier 2021. URL : http://

journals.openedition.org/studifrancesi/10008; DOI : https://doi.org/10.4000/studifrancesi.10008

Ce document a été généré automatiquement le 6 janvier 2021.

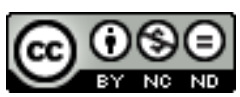

Studi Francesi è distribuita con Licenza Creative Commons Attribuzione - Non commerciale - Non opere derivate 4.0 Internazionale. 


\title{
F. Brunet, Théophile Gautier, écrivain et voyageur
}

\author{
Patrick Berthier
}

\section{RÉFÉRENCE}

FRANÇOIS BRUNET, Théophile Gautier, écrivain et voyageur, Paris, Honoré Champion, 2014,

pp. 504.

1 Ce livre est le dernier d'une trilogie dont les deux premiers tomes, chez le même éditeur, étaient Théophile Gautier et la musique (2006) et Théophile Gautier et la danse (2010). À travers cet ensemble se dessine l'exposé discret et sensible des raisons pour lesquelles l'auteur aime Gautier, sur lequel il a beaucoup écrit. La perspective adoptée, comme dans les deux précédents volumes, n'est pas celle d'une recherche érudite. Nous ne trouvons ici rien de littéralement nouveau sur les voyages de Gautier - sans doute n'était-ce pas le but de l'auteur, d'abord soucieux de lier les deux éléments de son titre: comment est-on écrivain quand on rédige des récits de voyage?

2 La composition du volume est simple. Une «Chronologie des voyages» (pp. 15-140) énumère de façon descriptive les déplacements de Gautier, du voyage en Belgique de 1836 jusqu'à l'inauguration du canal de Suez en 1869; François Brunet fait le choix d'y ajouter les Tableaux de siège, considérant que les allées et venues de Gautier entre Paris assiégé et Neuilly, son dernier domicile, sont une sorte de voyage désabusé. Cette première partie joue le rôle d'une biographie assez complète puisque, au fond, Gautier a réussi, malgré les obligations hebdomadaires de son feuilleton, à être bien plus souvent voyageur que nous n'aurions tendance à le penser. La deuxième partie, sur «L'écriture des voyages» (pp. 141-323), reprend exactement la première, non sur le plan factuel des déplacements de Gautier, mais pour proposer une typologie, générique notamment, des textes inspirés par le voyage et qui peuvent être tout autre chose que des «récits de voyage», des poèmes par exemple, ou cet amusant vaudeville d'Un voyage en Espagne (1843). La dernière partie (pp. 325-454) tente de cerner «La poétique du récit de voyage 
selon Théophile Gautier»: a-t-il des modèles? comment voyage-t-il? quel narrateur estil, tour à tour «extravagant» et "poético-réaliste»? quel rôle joue son attrait pour l'art ou pour «l'autre et l'ailleurs» dans son regard de voyageur? Bref, quel Gautier connaissons-nous lorsque nous lisons ce que ses voyages lui ont inspiré?

3 L'ensemble, qui se lit avec agrément, est complété par quelques annexes (dont un utile tableau exhaustif des textes de Gautier se rapportant au voyage, pp. 459-462), une bibliographie précise (mais pourquoi tous les titres d'articles sont-ils en italique, alors que les titres des périodiques où ils ont paru sont en romain?) et plusieurs index, dont un index géographique qui se justifie, étant donné le sujet du livre. Il serait possible de relever pas mal de défauts typographiques, entre autres trop de coquilles sur les noms propres («Van der Keyden» au lieu de «Heyden», p. 276, ou «Françoise MelmouxMontaubier» au lieu de «Marie-Françoise Melmoux-Montaubin», p. 310, et quelques autres) et aussi des erreurs de détail, non sur Gautier que l'auteur connaît comme sa poche, mais sur le «paysage» de son époque. Deux exemples, simplement: le titre de la «Chronique de Paris» ne prend pas d'article, et Balzac n'a pas «fondé» (p. 33) ce journal, mais l'a racheté pour son grand malheur; et les brillants feuilletons du vicomte de Launay (Delphine de Girardin) dans «La Presse» ne s'intitulent pas «Chronique de Paris» mais «Courrier de Paris» (p. 160); de plus, ladite «Presse» n'a pas été fondée en juin, mais en juillet 1836 (p. 159); et ainsi de suite. Certes, ce sont des négligences qui n'affectent pas le fond du développement, mais on en rencontre assez pour en être gêné, malgré tout. Ne restons pas, toutefois, sur ces scories, si regrettables soient-elles, mais signalons plutôt tels passages qui retiennent l'attention: sur la fortune du Voyage en Espagne et d'España (pp. 197-200), sur l'Algérie et la colonisation (pp. 242-243), ou sur le contraste entre Constantinople, où Gautier s'est ennuyé, et Athènes, qui lui a tant plu (pp. 255); on peut aimer aussi le ton libre de l'appréciation globale de François Brunet sur les qualités et les défauts de Gautier écrivain du voyage (pp. 321-323). Bref, ce livre plus subjectif que rigoureux attire la sympathie, à condition qu'on n'y cherche pas plus que ce qu'il donne dans ses meilleurs passages: le plaisir d'accompagner l'écrivain Gautier et de le mieux comprendre. 